\title{
The Use of The High-Performance Computing in The Learning Process
}

\author{
https://doi.org/10.3991/ijet.v16i17.22889 \\ Meruert Serik $^{1}$, Gulmira Yerlanova $\left.{ }^{1}{ }^{\varpi}\right)$, Nursaule Karelkhan ${ }^{1}$, \\ Nurlykhan Temirbekov ${ }^{2}$ \\ ${ }^{1}$ L.N.Gumilyov Eurasian National University, Nur-Sultan, Kazakhstan \\ ${ }^{2}$ Arkalyk Pedagogical Institute named after Y. Altynsarin, Arkalyk, Kazakhstan \\ gulmirka_78@mail.ru
}

\begin{abstract}
The need for specialists with high-performance computing skills is growing day by day. This is due to the fact that the high-performance process of processing big data is one of the most pressing problems today. This is especially important in science, economics, physical modeling, medicine, bioinformatics, weather forecasting, etc. This article analyzes the conditions for teaching high-performance computing, the experience of leading universities in the world, and it is established that teaching high-performance computing requires study. High performance computing training was carried out on 3 different hardware equipment (a personal computer, a supercomputer "Param-Bilim" India Kazakhstan Centre of Excellence in ICT [IKCOEICT] at L.N. Gumilyov Eurasian National University and a quantum computer in the cloud IBM Quantum Experience) using different algorithms in the $\mathrm{C}++$ and Phyton programming languages. The effectiveness of the calculation results in the educational process was determined as a result of the completed questionnaire.
\end{abstract}

Keywords-high-performance computing, education, supercomputer, educational process, personnel training

\section{Introduction}

It is known that in the modern world great changes and innovations are taking place in the field of computer technology, computing systems and computation methods. Especially multi-core computing systems, clusters, supercomputers, client-server technologies [1] began to be used in all areas of education and science, economics and industry. Problem solving and learning methods are also changing, and computing systems and computation methods are improving. In this regard, it is necessary to periodically update the features of training in high-performance computing.

High Performance Computing (HPC) is now accepted as a key enabling technology for scientific and industrial research; the phrase 'To Out-Compute is to Out-Compete' having been coined in the early 2000's and reinforced since by European, Chinese, Japanese and American initiatives in this area [2]. 
I chapter «Development of human capital» of the state program «Digital Kazakhstan» was said: «At the present time, there is a shortage specialists in ICT specialties with professional knowledge and skills in the chosen profession» [3]. This conclusion emphasizes the need to include in educational programs areas of training IT specialists with professional skills. It is known that a great contribution to the development of science and technology is made by the competence of IT specialists in the field of high-performance computing.

In the order of the minister of education and science of the Republic of Kazakhstan approved «On approval of the Standard Rules for the activities of educational organizations of the respective types»: The objective of the Higher education will be to train personnel with higher and postgraduate education by creating the necessary conditions for the development of educational programs aimed at the professional development and development of the individual based on the achievements of science and practice [4].

The past three decades witnessed a vast increase in the use of HPC across different scientific, engineering and business communities on problems such as sequencing the genome, predicting climate changes, designing modern aerodynamics, or establishing customer preferences [5].

$\mathrm{HPC}$ is an area that requires students to acquire knowledge in a wide range of topics. At the same time, HPC is not theoretical subject and is best learned through non-trivial projects. Teaching HPC therefore lives with the tension of having to cover many small, disconnected areas while wanting to provide more feedback on student projects [6].

Therefore, the training of qualified specialists in this area is not only one of the tasks of higher education, but also the need of modern society.

The interest of students of leading universities in high-performance computing is growing. The training requirements are high, so learning different methods of highperformance computing is very important for students. The characteristics of modern computers are high. Therefore, in the teaching of programming disciplines, quantum computers can be used to conduct high-performance computing in the educational process, which can be accessed through a cloud platform, personal computers and supercomputers.

The purpose of the research: Determination of theoretical foundations and practical implementation of training future specialists in the field of information technology in high performance computing.

To achieve this goal, the objectives of our research work were outlined in this article:

- to analyze the state of the use of high performance computing in higher education;

- to determine the hardware and software framework, used in high-performance computing;

- to determine the basics of implementing high performance computing in the educational process.

This includes conducting a theoretical analysis of high-performance computing, introducing special topics for teaching high-performance computing, defining special programming languages for teaching high-performance computing, defining special 
hardware for teaching high-performance computing, and teaching high-performance computing.

Currently, in universities, while studying the discipline of programming, we have introduced into the educational process topics related to high performance, learning a language and programming methods that are effective in high-performance computing and have demonstrated how to use computational tools.

\section{$2 \quad$ Literature review}

Currently, a large number of research papers and textbooks on the use of highperformance computing in the educational process in higher education are published.

In the book, «High performance computing: Modern systems and practices» Sterling T., Anderson M., Brodowicz M. authors domain scientists will learn how to use supercomputers as a key tool in their quest for new knowledge [7].

In the article, «High Performance Computing education in an Indian engineering institute» authors discusses the evolution and continuous upgrading of the HPC courses along with the issues and challenges experienced [8].

In the work, «Setting up and implementation of the parallel computing cluster in education» the authors describe in detail the setting up and implementation of the parallel computing cluster for education in the MatlLab environment and how they solved the problems arising on this way [9].

In the paper, «Introducing High Performance Computing concepts into engineering undergraduate curriculum: A success story» the authors discusses the process of teaching and evaluating the students with respect to HPC concepts [10].

In the work «Model of education and training strategy for the high performance computing» the authors focuses on the issue of a high performance computing education based on systems such as grid, cloud, HPC cluster or systems with hybrid environments [11].

In the work «Jupyter notebooks and user-friendly HPC access» the authors discusses a basic understanding of high performance computing is critical even for undergraduate students. Authors give students their own personal HPC sandbox, including access to a fully functional, personalized Jupyter Notebook server [12].

In the paper «High-Performance Computing and Engineering Educational Development and Practice» the authors show unique perspectives and practical experiences on student capability, oriented toward HPC curricular development [13].

Analysis of scientific literature and Internet resources shows that high performance computing still requires scientific research in Higher education.

\section{$3 \quad$ Materials and methods}

High performance computing training in higher educational institutions has a number of features. Various programming languages can be used in teaching high performance computing. In the definition of high-performance computational features 
of each of the programming languages, there are the following scientific studies published earlier.

Authors of work «Library for evolutionary algorithms in Python (LEAP)» pose here a new Python-based EC framework that uses an established generalized unified approach to EA concepts [14].

In the paper «Speeding-up the odetta calculation code for solving particle transport problems», authors consider and analyze a parallel version of the ODETTA calculation code using the Message Passing Interface library technology [15].

In the paper «Private and rateless adaptive coded matrix-vector multiplication» authors develop a private and rateless adaptive coded computation (PRAC) algorithm for distributed matrix-vector multiplication by taking into account [16] the privacy requirements of IoT applications and devices, and [17] the heterogeneous and time-varying resources of edge devices. They show that PRAC outperforms known secure coded computing methods when resources are heterogeneous [18].

Computing has been advanced to HPC throughout the past decades. However, undergraduate students are still lacking of experience in how HPC functions, because curricula do not adequately cover HPC contents [19]. To solve this problem, we have included in the content of disciplines topics about high-performance computing hardware and the basics of working with them. which were implemented in the educational process. As a means of implementing our calculations were taken a personal computer, a supercomputer Kazakh-Indian Training Center for Information and Communication Technologies, Param-Bilim IKCEICT in Eurasian National University L. N. Gumilyov and a 5-qubit quantum computer in the cloud IBM Quantum Experience.

\subsection{Characteristics of hardware devices used in computing}

1. Characteristics of a personal computer: processor Intel ${ }^{\circledR}$ Core ${ }^{\mathrm{TM}} \mathrm{i} 5-2410 \mathrm{M}$ CPU@2.3Ghz, 2.3Ghz, RAM 3 G.

2. Param bilim HPC facility is based on indigenous technologies developed by C-DAC. The HPC facility includes the nodes equipped with 5110p Xeon Phi, nVidia K20X Card, NAS storage with 20 TB of usable storage space and RCS cards. The facility has HPC Portal 'CHReME' for resource management and 'ONAMA' for scientific and engineering applications installation and execution. It will have applications ported in broad areas like Weather Forecasting and Bioinformatics [20].

3. IBM Quantum Experience - it is an online platform that provides users with cloudbased access to the most advanced quantum computers [21].

All calculations were performed on this hardware using various algorithms and the results were compared. 


\section{$4 \quad$ Results of research}

In the experiment on the introduction of high-performance computing in the educational process, took part the students of L. N. Gumilyov Eurasian National University on the educational program of the Bachelor of Informatics and Shakarim University on the educational programs of the Bachelor of Information Systems and Computer Engineering and Software. The number of respondents is about 100 people. The content of several courses of these educational programs is supplemented by several topics on high-performance computing.

In the syllabus of the course "Algorithmization and Programming" on the educational program informatics of L.N. Gumilyov Eurasian National University introduced topics: methods of sorting arrays, high-performance methods of sorting arrays, methods for calculating a definite integral (number pi), multiplying a matrix by a vector, increasing the speed of multiplying a matrix by a vector using the vectorization method.

For these topics in the educational process, task programs were developed on $\mathrm{C}++$ и Python, the results were compared, effective algorithms and programming environment were determined.

Depending on the type of task, a high-performance programming language, hardware, and an efficient method were selected. As one of such problems in our article, we gave several options for calculating the value of a definite integral (known number pi) up to 10,000 characters and indicated a rational method, an efficient algorithm and a programming language. The calculations were carried out on several computing devices.

We can say that calculating the value of a definite integral (number pi) up to a trillion symbols has no significant practical value. It turns out, that to launch a rocket, the value of the number pi up to 15 characters [22] is enough. However, improving its calculating formula, the value of offering up to a trillion characters, install world records in computing its value.

The most accurate alue of pi is 50 trillion digits, and was achieved by Timothy Mullicam on 29 January 2020 [23].

There are many known ways to determine the value of a definite integral (pi), such as the Bailey-Borwein-Plouffe method, the Chudnovsky method, the Monte Carlo's method, the Bellard's method, etc. In our article, we examined several of these methods and identified an effective algorithm. First, the calculations were carried out in languages $\mathrm{C}++$ и Python using the formula Bailey-Borwein-Plouffe [Bailey-BorweinPlouffe's formula]:

$$
\pi=\sum_{n=0}^{\infty} \frac{1}{16^{n}}\left(\frac{4}{8 n+1}-\frac{2}{8 n+4}-\frac{1}{8 n+5}-\frac{4}{8 n+6}\right)
$$

At the first stage, the program code was written using these algorithms on $\mathrm{C}++$ и Python and the results were compared.

Program code in Python:

from time import time
Program code in $\mathrm{C}++[24]$ :

\#include <iostream>

\#include <cmath> 


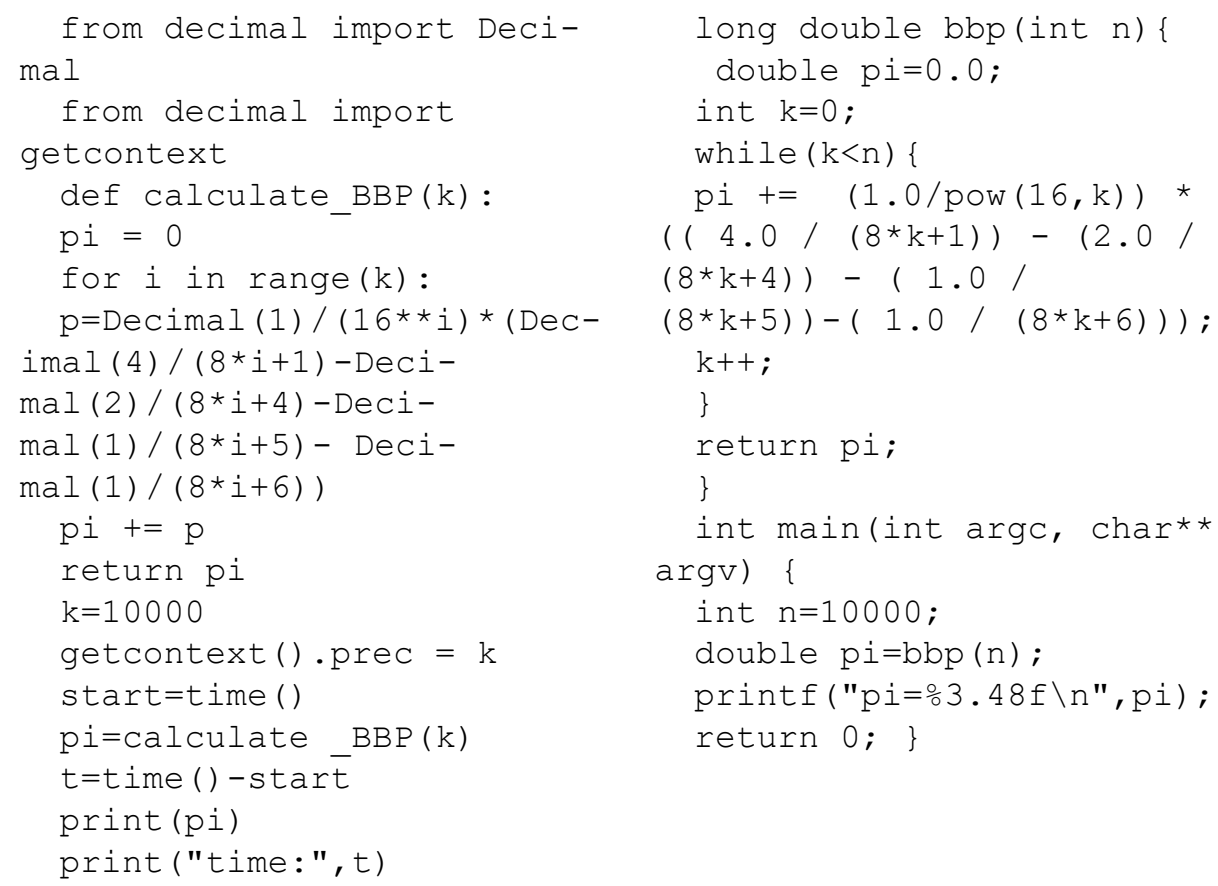

We noticed that a program written in $\mathrm{C}++$ according to a given algorithm can calculate the value of a definite integral (pi) only up to 48 characters, bur in language Python up to 10,000 characters. However, it should be noted that $\mathrm{C}++$ is a more productive language than Python.

At the second stage, the calculations were performed first on a personal computer (figure 1). 


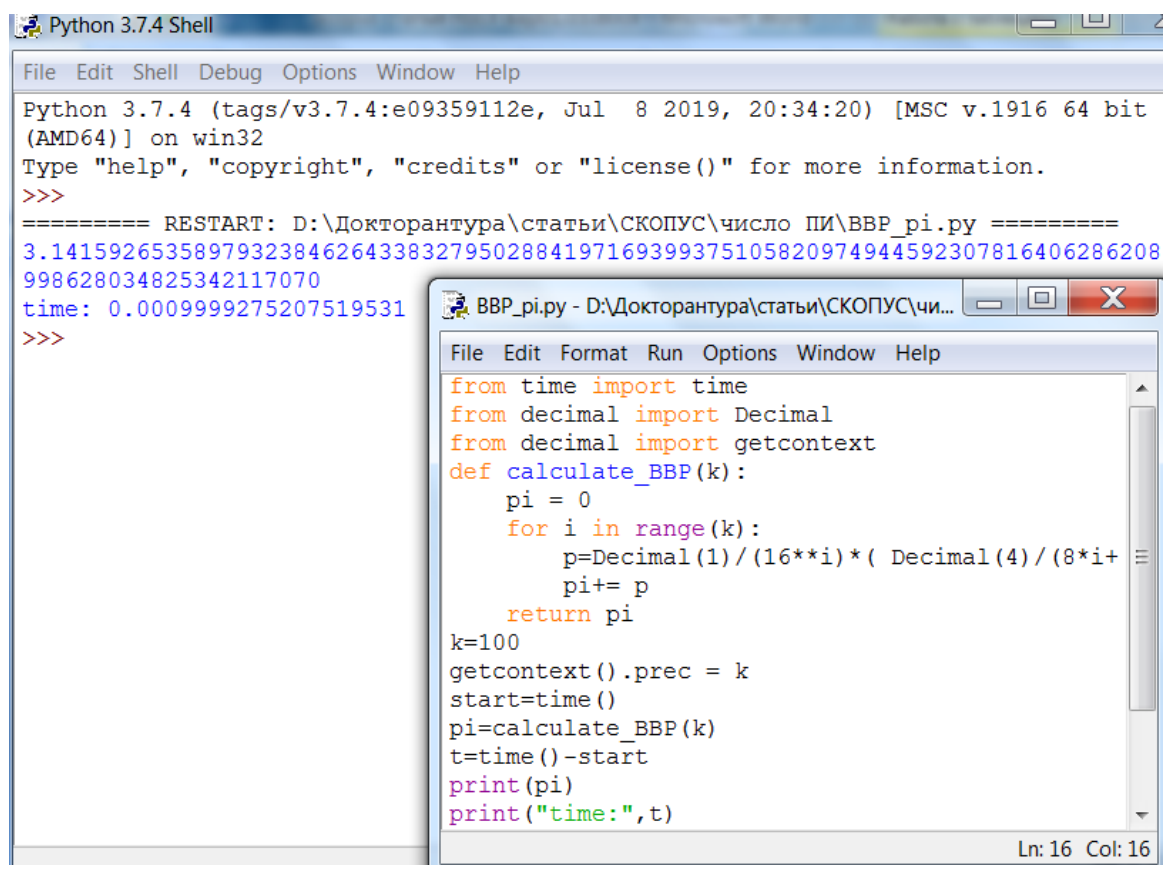

Fig. 1. Computing in language Python on a personal computer and its result $(n=100)$

Then the calculations were carried out on the second hardware - a supercomputer «Param-Bilim» of Eurasian National University L. N. Gumilyov. Its use was organized remotely. Due to the current pandemic, faculty members have been given VPN access to use university resources for their discipline. Thus, we were able to connect to a supercomputer.

For working with a supercomputer Param-Bilim as a program that provides work with the server, was used Putty. It allows you to Linux connect to the server using the protocol SSH (figure 2): 
Paper-The Use of The High-Performance Computing in The Learning Process

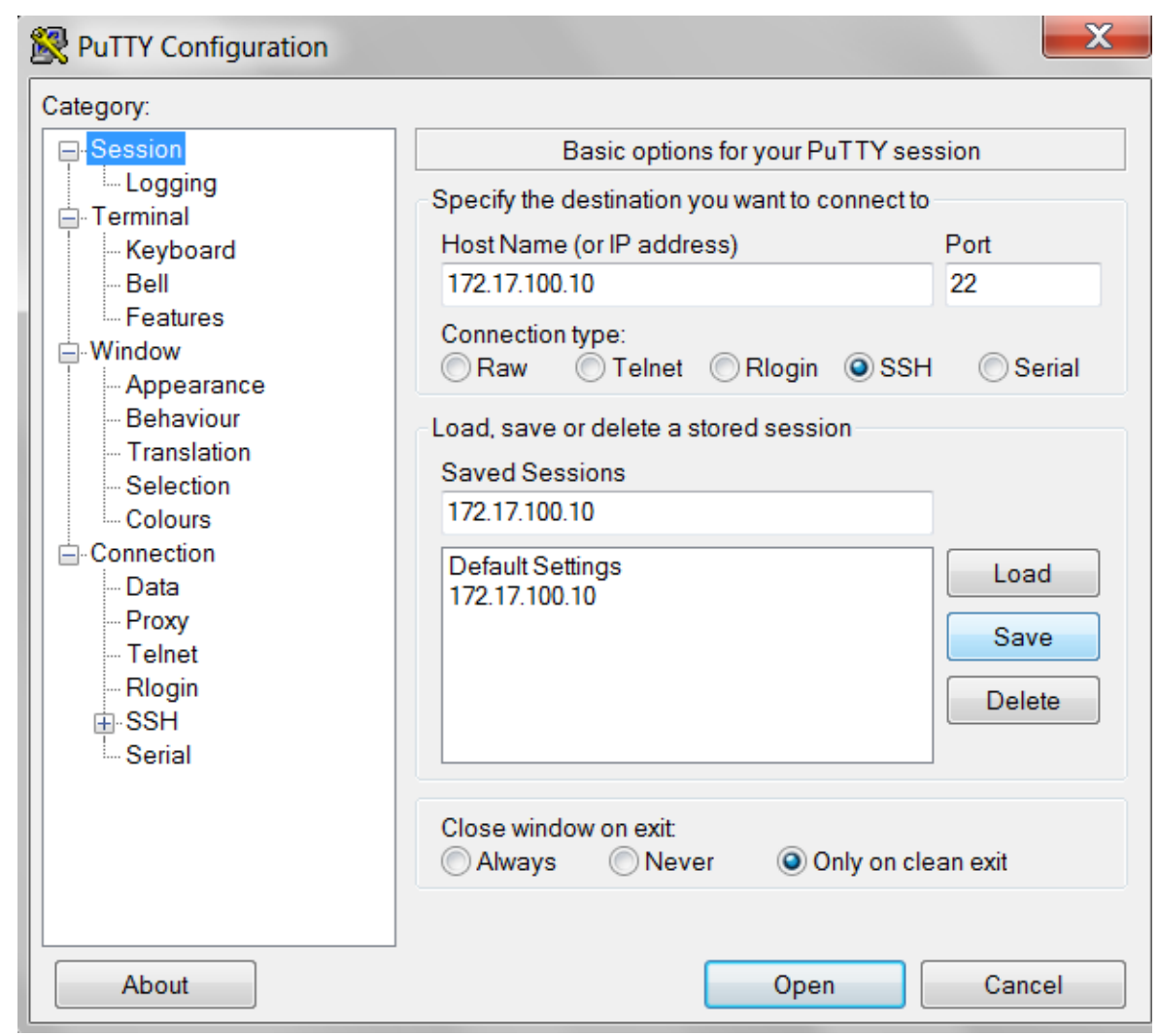

Fig. 2. Connecting to a Linux server

Enter the username and password of the user, go to the remote Linux servers window and after creating a new file, enter the necessary program lines (figure 3 ):

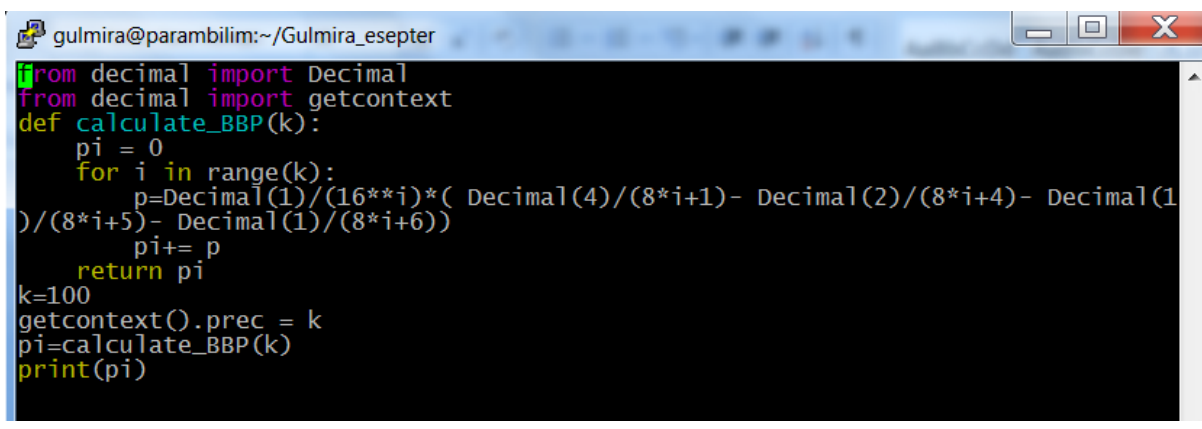

Fig. 3. Program code

The result of the executed program (figure 4): 


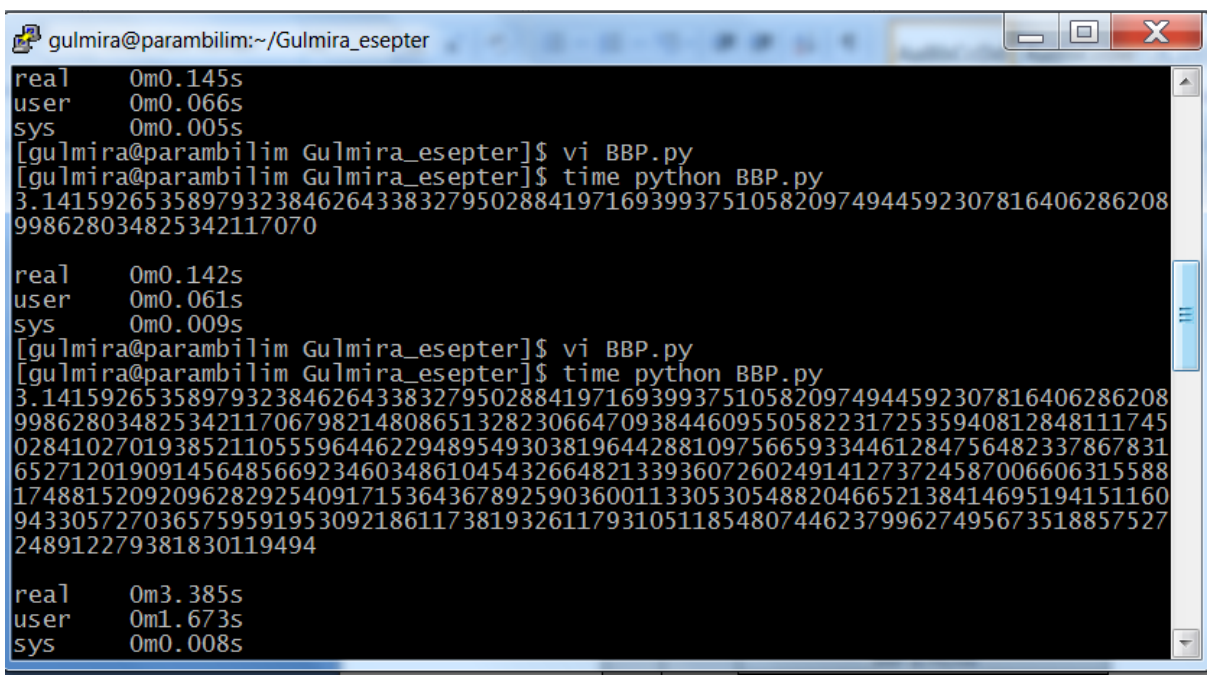

Fig. 4. Results of calculations at $n=100$ и $n=500$

The third hardware is a quantum computer located on a cloud platform IBM Quantum Experience. There, the calculations were carried out using Quantum lab. First, we register on the cloud platform IBM Quantum Experience and go to the section Quantum lab (figure 5).

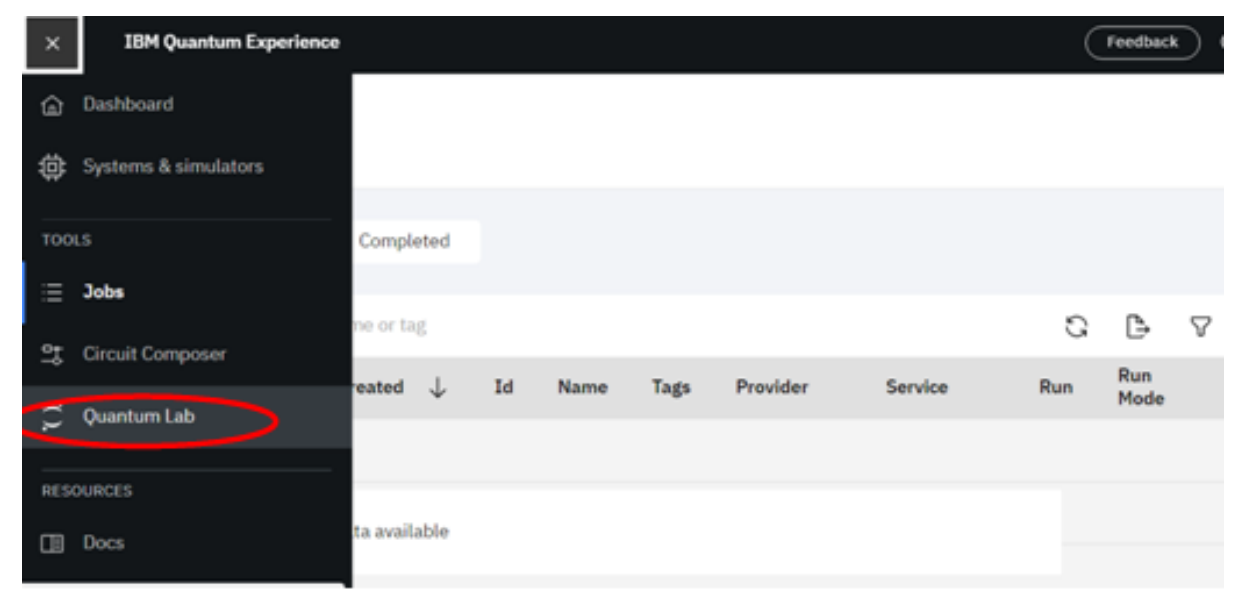

Fig. 5. Quantum lab

Create a new file and write the program code (figure 6). 


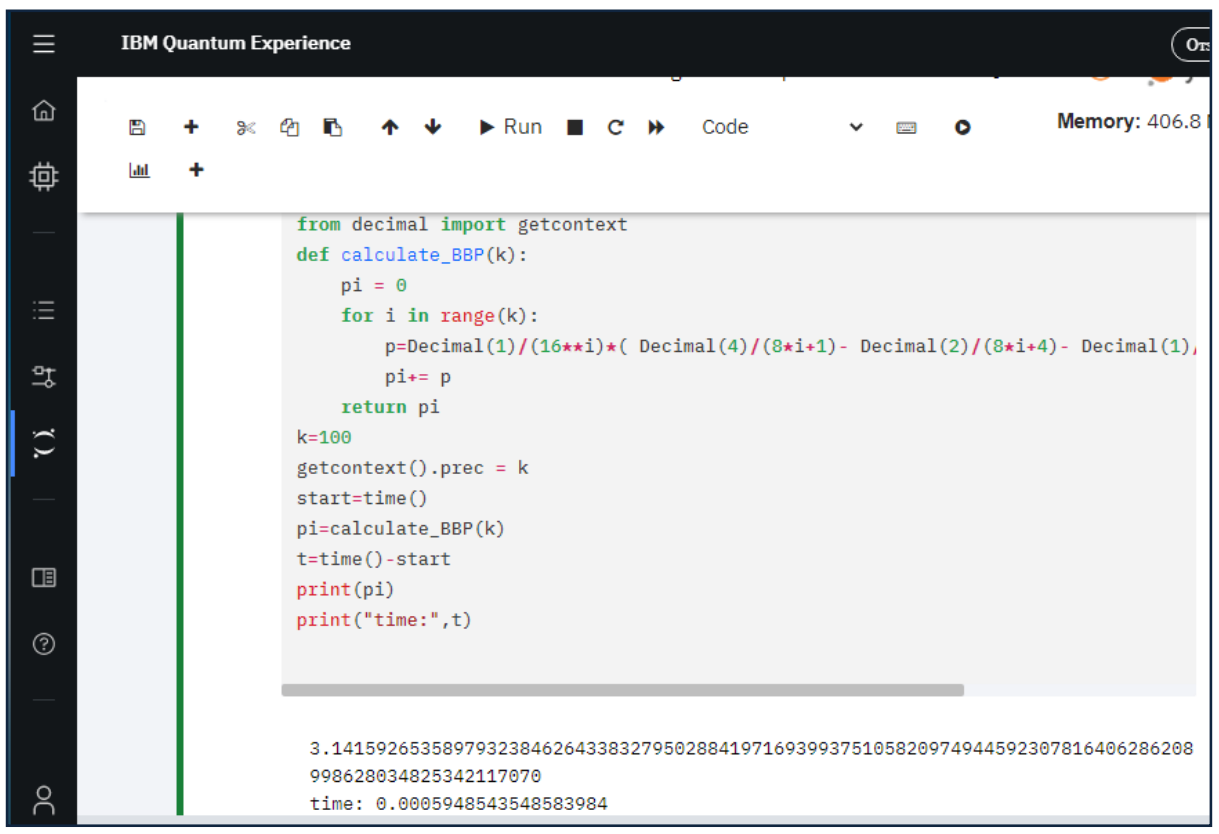

Fig. 6. The result of calculating the definite integral (number pi)

Results of calculations performed on a personal computer, supercomputer and quantum computer located in the cloud on an online platform IBM Quantum Experiences, are presented in the following tables (table 1, table 2).

Table 1. Results of calculations on a personal computer and a quantum computer using Bailey-Borwein-Plouffe algorithm

\begin{tabular}{|l|c|c|c|c|}
\hline \multirow{2}{*}{ № } & \multirow{2}{*}{$\mathbf{n}$} & \multicolumn{3}{|c|}{ BBP in Phyton } \\
\cline { 3 - 5 } & & Computer & IBM Quantum & acceleration coefficient \\
\hline 1 & 100 & 0,0009 & 0,0008 & 1,125 \\
\hline 2 & 500 & 0,022 & 0,023 & 0,956522 \\
\hline 3 & 1000 & 0,173 & 0,1547 & 1,118293 \\
\hline 4 & 2000 & 1,097 & 0,8672 & 1,264991 \\
\hline 5 & 3000 & 3,235 & 2,9365 & 1,101652 \\
\hline 6 & 4000 & 7,694 & 6,7012 & 1,148153 \\
\hline 7 & 5000 & 12,381 & 10,9494 & 1,130747 \\
\hline 8 & 6000 & 20,864 & 17,9312 & 1,163558 \\
\hline 9 & 7000 & 31,459 & 28,2737 & 1,112659 \\
\hline 10 & 8000 & 46,464 & 41,1054 & 1,130362 \\
\hline 11 & 9000 & 65,729 & 57,4261 & 1,144584 \\
\hline 12 & 10000 & 92,066 & 82,9312 & 1,110149 \\
\hline
\end{tabular}


Table 2. Results of calculations on a supercomputer Param Bilim according to BaileyBorwein-Plouffe algorithm

\begin{tabular}{|l|c|c|c|c|c|c|}
\hline \multirow{2}{*}{$\begin{array}{l}\text { BBP in } \\
\text { Phyton }\end{array}$} & \multirow{2}{*}{$\mathbf{t}$} & \multicolumn{5}{|c|}{$\mathbf{n}$} \\
\cline { 3 - 7 } & & $\mathbf{1 0 0}$ & $\mathbf{5 0 0}$ & $\mathbf{1 0 0 0}$ & $\mathbf{2 0 0 0}$ & $\mathbf{3 0 0 0}$ \\
\hline \multirow{2}{*}{ Super } & real & $\mathrm{m} 0.142 \mathrm{~s}$ & $0 \mathrm{~m} 3.385 \mathrm{~s}$ & $0 \mathrm{~m} 23.899 \mathrm{~s}$ & $2 \mathrm{~m} 59.439 \mathrm{~s}$ & $\mathrm{~m} 48.830 \mathrm{~s}$ \\
computer & user & $0 \mathrm{~m} 0.061 \mathrm{~s}$ & $0 \mathrm{~m} 1.673 \mathrm{~s}$ & $0 \mathrm{~m} 11.923 \mathrm{~s}$ & $1 \mathrm{~m} 29.616 \mathrm{~s}$ & $4 \mathrm{~m} 54.090 \mathrm{~s}$ \\
& sys & $0 \mathrm{~m} 0.009 \mathrm{~s}$ & $0 \mathrm{~m} 0.008 \mathrm{~s}$ & $0 \mathrm{~m} 0.019 \mathrm{~s}$ & $0 \mathrm{~m} 0.060 \mathrm{~s}$ & $0 \mathrm{~m} 0.158 \mathrm{~s}$ \\
\hline
\end{tabular}

Comparison of the results of finding the value of a definite integral (number pi) up to 10,000 characters on a personal computer and a quantum computer is represented by a diagram (figure 7).

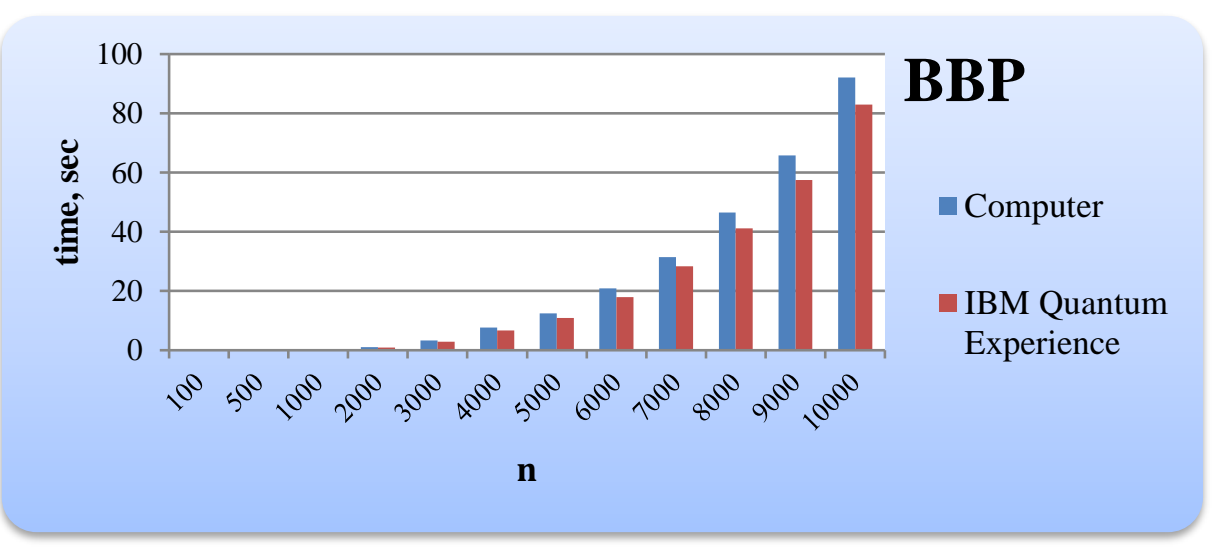

Fig. 7. Comparison of a personal computer and a quantum computer

In the same way, using Bellard's formula, we calculated the value of the definite integral (pi value) up to 10,000 characters on different hardware.

Bellard's formula:

$$
\pi=\frac{1}{2^{6}} \sum_{n=0}^{\infty} \frac{(-1)^{n}}{2^{10 n}}\left(-\frac{2^{5}}{4 n+1}-\frac{1}{4 n+3}+\frac{2^{8}}{10 n+1}-\frac{2^{6}}{10 n+3}-\frac{2^{2}}{10 n+5}-\frac{2^{2}}{10 n+7}+\frac{1}{10 n+9}\right)
$$

In our case, we compared the results of the Bailey-Borwein-Plouffe and Bellard algorithms, and note that the Bailey-Borwein-Plouffe algorithm is fast on both hardware. (table 3).

Table 3. The result of comparing the Bailey-Borwein- Plouffe and Bellard algorithms

\begin{tabular}{|c|c|c|c|c|c|c|c|}
\hline \multirow{2}{*}{ № } & \multirow{2}{*}{$\mathbf{n}$} & \multicolumn{2}{|c|}{ Computer, sec } & \multirow{2}{*}{$\begin{array}{l}\text { acceleration } \\
\text { coefficient }\end{array}$} & \multicolumn{2}{|c|}{ IBM Quantum, sec } & \multirow{2}{*}{$\begin{array}{c}\text { acceleration } \\
\text { coefficient }\end{array}$} \\
\hline & & $B B P$ & Bellard & & $B B P$ & Bellard & \\
\hline 1 & 100 & 0,0009 & 0,002 & 2,2222 & 0,0006 & 0,0011 & 1,8333 \\
\hline 2 & 500 & 0,022 & 0,073 & 3,3182 & 0,0250 & 0,0643 & 2,5720 \\
\hline 3 & 1000 & 0,173 & 0,481 & 2,7803 & 0,1547 & 0,4111 & 2,6574 \\
\hline 4 & 2000 & 1,097 & 3,480 & 3,1723 & 0,8672 & 3,0227 & 3,4856 \\
\hline
\end{tabular}




\begin{tabular}{|l|c|c|c|c|c|c|c|}
\hline 5 & 3000 & 3,235 & 11,471 & 3,5459 & 2,9365 & 9,9862 & 3,4007 \\
\hline 6 & 4000 & 7,694 & 29,209 & 3,7963 & 6,7012 & 23,3743 & 3,4881 \\
\hline 7 & 5000 & 12,381 & 48,631 & 3,9279 & 10,9494 & 42,8407 & 3,9126 \\
\hline 8 & 6000 & 20,864 & 83,770 & 4,0150 & 17,931 & 73,48276 & 4,0980 \\
\hline 9 & 7000 & 31,459 & 131,074 & 4,1665 & 28,2737 & 115,4847 & 4,0845 \\
\hline 10 & 8000 & 46,464 & 198,390 & 4,2698 & 41,1054 & 167,8101 & 4,0824 \\
\hline 11 & 9000 & 65,729 & 276,030 & 4,1995 & 57,426 & 242,306 & 4,2194 \\
\hline 12 & 10000 & 92,066 & 376,679 & 4,0914 & 82,931 & 332,828 & 4,0133 \\
\hline
\end{tabular}

Comparing the above results (figure 8), you can notice that the speed of a quantum computer located in the cloud on an online platform IBM Quantum Experience higher than a personal computer. So, in our case, a quantum computer has become an effective hardware tool.

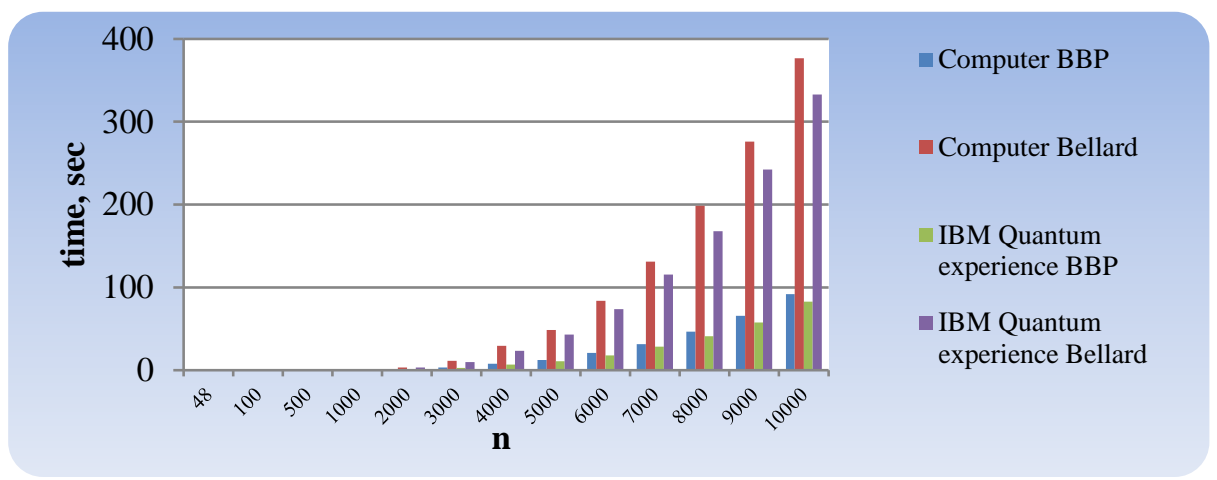

Fig. 8. Comparison of calculations on a personal computer and a quantum computer using different algorithms

As the result of the calculation showed, as the value of $\mathrm{n}$ increased, the speed coefficient also increased. In our case, with a value of $n=10000$, the speed factor was 4. The most efficient of the two algorithms was the Bailey-Borwein-Plouffe algorithm.

Apart from these methods, at the we have shown a vectorization method for calculating the multiplication of matrices by a vector.

When studying the discipline "Algorithmization and Programming" to calculate a definite integral (number pi), sorting algorithms by bubble method, Shell and Hoare sorting (quick sort), applications of the vectorization method for calculating the multiplication of a matrix by a vector we used 3 hardware devices.

\section{$5 \quad$ Discussions and conclusions}

As a result of the set goal of "Determining the theoretical foundations and practical implementation of the training of future specialists in the field of information technology for high-performance calculations": 
1. The conditions for teaching high-performance computing, the experience of the world's leading universities and scientific papers published in research journals with a high rating are analyzed. As a result, it was found that learning high performance computing requires learning;

2. It was found that in higher educational institutions it is possible to use various hardware equipment used in teaching high-performance computing, as well as various programming languages. As a result, methods were chosen for constructing programs using 3 different hardware equipment for the educational process, using various high-performance computing algorithms in the $\mathrm{C}++$ and Phyton programming languages;

3. In the content of the discipline "Algorithmization and Programming" of L.N. Gumilyov Eurasian National University themes included: methods for sorting arrays, high-performance methods for sorting arrays, methods for calculating a definite integral (number pi), multiplying a matrix by a vector, increasing the speed of multiplying a matrix by a vector using the vectorization method. Shows how to use a personal computer, a Param-Bilim supercomputer and a quantum computer on the IBM Quantum Experience cloud platform in the educational process.

Based on the results of the survey, it was found that the method of teaching highperformance computing is effective.

\section{$6 \quad$ References}

[1] Serik, M., Mukhambetova, M., Yeskermessuly A. Improving the Content of a Client-server Technology Training Course: Set up and Collaborative Implementation of Local and Cloudbased Remote Servers (iJET), 14(21): 191-204. https://doi.org/10.3991/ijet.v14i21.10643

[2] The Impact of National High Performance Computing An analysis of the impacts and outputs of investment in national HPC Dr. Edward Clarke Dr. Iain Larmour August 2016. https://epsrc.ukri.org/newsevents/pubs/impactofnationalhpc/

[3] State programmer «Digital Kazakhstan» approved by a decree of Government of the Republic of Kazakhstan of "12" December 2017 № 827. https://digitalkz.kz/wp-content/uploads/2020/03/ГП\%20ЦК\%20на\%20англ\%2003,06,2020.pdf

[4] On approval of the Standard Rules for the activities of educational organizations of the respective types. http://adilet.zan.kz/eng/docs/V1800017657

[5] Raj, R.K., Romanowski, C.J, Impagliazzo, J., Aly, S.G., Becker, B.A., Chen, J., Ghafoor, S., Giacaman, N., Gordon, S.I., Izu, C., Rahimi, S., Robson, M.P., Thota, N. High Performance Computing Education: Current Challenges and Future Directions . https://doi.org/10.1145/3437800.3439203

[6] Zarestky, J., Bangerth, W. Teaching high performance computing: Lessons from a flipped classroom, project-based course on finite element methods (2014) Proceedings of EduHPC 2014: Workshop on Education for High-Performance Computing - Held in Conjunction with SC 2014: The International Conference for High Performance Computing, Networking, Storage and Analysis, art. no. 7016356, pp. 34-41. ISBN: 978-147997021-6. https://doi. org/10.1109/eduhpc. 2014.10

[7] Sterling, T., Anderson, M., Brodowicz, M. High performance computing: Modern systems and practices (2017) High Performance Computing: Modern Systems and Practices, pp. 1- 
689. http://www.sciencedirect.com/science/book/9780124201583 ISBN: 978-0124202153; 978-012420158-3. https://doi.org/10.1016/b978-0-12-420158-3.00011-3

[8] Neelima. High Performance Computing education in an Indian engineering institute. (2017) Journal of Parallel and Distributed Computing, 105, pp. 73-82. http://www.elsevier.com/ inca/publications/store/6/2/2/8/9/5/index.htt. https://doi.org/10.1016/j.jpdc.2017.01.019

[9] Serik, M., Karelkhan, N., Kultan, J., Zulpykhar, Zh. Setting up and implementation of the parallel computing cluster in education. International Journal of Emerging Technologies in Learning (iJET), 14(6): 4-17. https://doi.org/10.3991/ijet.v14i06.9736

[10] Neelimay, B., Li, J. Introducing High Performance Computing concepts into engineering undergraduate curriculum : A success story (2015) Proceedings of EduHPC 2015: Workshop on Education for High-Performance Computing - Held in conjunction with SC 2015: The International Conference for High Performance Computing, Networking, Storage and Analysis, art. no. 6. ISBN: 978-145033961-2. https://doi.org/10.1145/2831425.2831430

[11] Škrinarová, J., Vesel, E. Model of education and training strategy for the high performance computing (2016) ICETA 2016 - 14th IEEE International Conference on Emerging eLearning Technologies and Applications, Proceedings, art. no. 7802080, pp. 315-320. ISBN:978150904701-7. https://doi.org/10.1109/iceta.2016.7802080

[12] Glick, B., MacHe, J. Jupyter notebooks and user-friendly HPC access (2019) Proceedings of EduHPC 2018: Workshop on Education for High-Performance Computing, Held in conjunction with SC 2018: The International Conference for High Performance Computing, Networking, Storage and Analysis, art. no. 8638386, pp. 11-20. http://ieeexplore.ieee.org/xpl/mostRecentIssue.jsp?punumber=8630310 ISBN: $\quad 978-172810190-3$. https://doi.org/10.1109/eduhpc.2018.00005

[13] Chen, J., Impagliazzo, J., Shen, L.High-Performance Computing and Engineering Educational Development and Practice (2020) Proceedings - Frontiers in Education Conference, FIE, 2020-October, art. no. 9274100. ISBN: 978-172818961-1. https://doi.org/10.1109/ fie44824.2020.9274100

[14] Coletti, M.A., Scott, E.O., Bassett, J.K. Library for evolutionary algorithms in Python (LEAP) GECCO 2020 Companion - Proceedings of the 2020 Genetic and Evolutionary Computation Conference Companion8 July 2020, Pages 1571-1579. https://doi.org/10 $.1145 / 3377929.3398147$

[15] Shoshina A.,V., Belousov V., I Speeding-Up The Odetta Calculation Code For Solving Particle Transport Problems Izvestiya Wysshikh Uchebnykh Zawedeniy, Yadernaya EnergetikaVolume 2020, Issue 4, 9 November 2021, Pages 130-141 .https://doi.org/ $10.26583 /$ npe. 2020.4 .12

[16] Bitar, R., Xing, Y., Keshtkarjahromi, Y., Dasari, V., El Rouayheb, S., Seferoglu, H. PRAC: Private and rateless adaptive coded computation at the edge (2019) Proceedings of SPIE The International Society for Optical Engineering, 11013, art. no. 110130T. http://spie.org/x1848.xml ISBN: 978-151062691-1. https://doi.org/10.1117/12.2519768

[17] Keshtkarjahromi, Y., Xing, Y., Seferoglu, H.Dynamic Heterogeneity-Aware Coded Cooperative Computation at the Edge (2018) Proceedings - International Conference on Network Protocols, ICNP, 2018-September, art. no. 8526801, pp. 23-33. ISBN: 978153866043-0. https://doi.org/10.1109/icnp.2018.00013

[18] Bitar, R., Xing, Y ,Keshtkarjahromi, Y.,,Dasari, V, El Rouayheb, S, Seferoglu, H. Private and rateless adaptive coded matrix-vector multiplication Eurasip Journal on Wireless Communications and Networking Volume 2021, Issue 1, December 2021. https://doi.org/ 10.1186/s13638-020-01887-y 
[19] Cui S., Wang Y., Li L., Peng X., Yalvas B. Introducing high performance computing to undergraduate students Computers in Education Journal Volume 16, Issue 4, 2016, Pages 104-112 , ISSN: 10693769

[20] Param Bilim Project Handbook, India - Kazakhstan Centre of Excellence in ICT [IKCOEICT] at Eurasian National University, Astana.

[21] https://quantum-computing.ibm.com

[22] https://zen.yandex.com/media/popsci/pochemu-nasa-do-sih-por-ispolzuet-chislo-pi-vsegolish-s-15-znakami-posle-zapiatoi-hotia-ego-uje-vychislili-do-314-trln$\underline{5 e 68 a 796664 b e 20 c e b 797 f 76}$

[23] https://www.guinnessworldrecords.com/world-records/66179-most-accurate-value-of-pi

[24] A.U. Manaqbaev «Jogary jyldamdyqty eseptewlerdi oku procesine endirudyn adistemelik negizderi» magistirlıg dissertasya, Eurasian National University, 2019

\section{$7 \quad$ Authors}

Meruert Serik professor, doctor of pedagogical sciences, Department of Computer Sciences, Faculty of Information Technology, L.N. Gumilyov Eurasian National University, Nur-Sultan, Kazakhstan (E-mail: serik_meruerts@mail.ru).

Gulmira Yerlanova, doctoral student, Department of Computer Sciences, Faculty of Information Technology, L.N. Gumilyov Eurasian National University, Nur-Sultan, Kazakhstan (E-mail: gulmirka_78@mail.ru)

Nursaule Karelkhan association professor, PhD, Department of Computer Sciences, Faculty of Information Technology, L.N. Gumilyov Eurasian National University, Nur-Sultan, Kazakhstan (E-mail: knursaule@mail.ru).

Nurlykhan Temirbekov, candidate of technical science, vice-rector of Arkalyk Pedagogical Institute named after Y.Altynsarin, Arkalyk, Kazakhstan (E-mail: Vicerector@api.kz).

Article submitted 2021-03-25. Resubmitted 2021-06-04. Final acceptance 2021-06-22. Final version published as submitted by the authors. 